\title{
Anti-Stress Action of a Corticotropin- Releasing Factor Antagonist on Behavioral Reactivity to Stressors of Varying Type and Intensity
}

Stephen C. Heinrichs, Ph.D., Frédérique Menzaghi, Ph.D., Emilio Merlo Pich, M.D., Helen A. Baldwin, Ph.D., Stefanie Rassnick, Ph.D., Karen T. Britton, M.D., Ph.D., and George F. Koob, Ph.D.

Central administration of a Corticotropin-Releasing Factor (CRF) antagonist is well documented to attenuate a variety of behavioral responses to several distinct stressors; however, it is not yet clear whether the activation of CRF neurons is dependent on the type or intensity of the experimental stressor, or rather on the particular behavioral response to stress under study. To test the generality of the stress-protective effect of the $C R F$ antagonist, $\alpha$-helical $C R F_{9-41,}(1,5$ or $25 \mu g$ intracerebroventricularly), the present experiments employed a sensitive index of anxiogenic-like behavior by measuring suppression in exploration on the elevated plus-maze following exposure to social, swim, or restraint stressors. A 1 but not 5 or $25 \mu \mathrm{g}$ dose of the CRF antagonist administered just prior to social, swim, or restraint stress reversed the stress-induced inhibition of exploratory behavior. Chlordiazepoxide and the steroid anesthetic, alphaxalone, also attenuated the anxiogeniclike effect of restraint stress and elevated the baseline exploratory behavior of nonstressed control groups. Although the stressors produced a graded secretion of adrenocorticotropin $(A C T H)$ with the ranking restraint $>$ swim $>$ social, the relative amplitude of behavioral reactivity to social, swim, and restraint stress was comparable. The relative efficacy of the CRF antagonist to reverse the stressor effects was also comparable. These results suggest that antagonism of activated brain CRF systems attenuates the behavioral response to stress regardless of the type or intensity of the stressor as measured by ACTH secretion.

[Neuropsychopharmacology 11:179-186, 1994]
KEY WORDS: CRF; Stress; Plus-maze; Chlordiazepoxide; Alphaxalone; ACTH; Corticosterone

A role for endogenous brain corticotropin-release factor (CRF) systems in coordinating the behavioral response to stress is substantiated by anti-stress actions

From the Scripps Research Institute, Department of Neuropharmacology (SCH, FM, EMP, HAB, SR, GFK), CVN7, and the San Diego Veterans Administration Medical Center, Department of Psychiatry (KTB), La Jolla, California.

Address correspondence to: Stephen $\mathrm{C}$. Heinrichs, Neurocrine Biosciences, Inc., 3050 Science Park Rd., San Diego, CA 92121.

Received September 20, 1993; revised May 10, 1994; accepted May 31, 1994. of a CRF antagonist, $\alpha$-helical CRF9-41. Central administration of this competitive antagonist of CRF (Rivier et al. 1984) reverses or attenuates the suppression of ingestive, exploratory, and operant behaviors produced by administration of CRF or exposure to various stressors (see Dunn and Berridge 1990). A major biological question is the specificity of the role of CRF in relationship to the type or the severity of the stressor (Koob et al. 1993). For instance, exposure to stressors such as physical restraint, ethanol withdrawal, novelty, or social defeat effectively suppresses subsequent exploration of an unfamiliar environment, and in each case this anxiogenic-like action is blocked by 
central administration of a CRF antagonist (Dunn and Berridge 1990; Baldwin et al. 1991; Heinrichs et al. 1992). In contrast, endogenous CRF systems do not appear to modulate unconditioned behavioral reactivity in stressful situations involving acoustic startle stimuli (Swerdlow et al. 1989) or operant conflict responding (Britton et al. 1986). Thus, available evidence suggests that the behavioral measure selected for study is more important than the type or intensity of the stressor in determining whether or not brain CRF systems modulate the behavioral response to stress. One strategy for further testing this hypothesis is to select several different stressors and examine the generality of the antistress action of the CRF antagonist on a single behavioral measure of stressor reactivity.

Hormonal release from the pituitary and adrenal glands has been quantified experimentally to gauge the presence and intensity of the physiological effects of various stressors (Keim and Sigg 1976; Natelson et al. 1981, 1988; Kant et al. 1983; Gibbs 1984; Pitman et al. 1988; Orr et al. 1990). Plasma adrenocorticotropic hormone $(\mathrm{ACTH})$ and corticosterone levels are responsive to the onset of stress and directly influenced by the major hypothalamic releasing factor for ACTH, CRF (De Souza and Van Loon 1985; Gibbs 1984). Hence, the present study employed plasma ACTH and corticosterone levels as possible indices of differential physiological activation produced by three stressors: restraint, swimming, and social conflict.

Restraint, swimming, and social conflict all have different characteristics that allow testing of the generality of the anti-stress effects of $\alpha$-helical $\mathrm{CRF}_{9-41}$. Restraint in the prone position produced by placing a naive animal inside of a hemi-cylindrical Plexiglas enclosure is a frequently employed stressor that stimulates the hypothalamo-pituitary-adrenal axis (De Souza and Van Loon 1985), increases catecholamine turnover (Keim and Sigg 1976), produces immunosuppression (Farabollini et al. 1993), and increases anxiogenic-like behavior (Berridge and Dunn 1989). Corticotropin releasing factor antagonist administration just prior to 40 to 60 minutes of restraint has been reported to reverse the anorexic and neophobic effects of stress (Krahn et al. 1986; Berridge and Dunn 1987; Shibasaki et al. 1988). The present study tested the ability of $\alpha$-helical $\mathrm{CRF}_{9-41}$ administered centrally and the anxiolytic compounds chlordiazepoxide and alphaxalone administered peripherally prior to a restraint stressor to attenuate the suppression of exploratory behavior on the elevated plus-maze. Forced swimming at ambient water temperatures is a stressor that activates the hypothalamo-pituitary-adrenal axis and produces an anxiogenic-like behavioral response on the plus-maze (Britton et al. 1992). Although this physiological and behavioral profile is shared with restraint, the swim stressor requires bodily exertion, whereas restraint stress in contrast is designed to limit movement. The distinctly active as opposed to passive coping strategy employed following the initiation of swimming is a valuable context in which to test the generality of the antistress action of the CRF antagonist. Finally, social conflict stress involving threat from an aggressive male counterpart rat has been described previously to suppress exploration of the plus-maze (Heinrichs et al. 1992). The CRF antagonist, $\alpha$-helical $\mathrm{CRF}_{9-41}$ at a $25 \mu \mathrm{g}$ dose, reversed the behavioral response to social defeat when administered immediately post-stress and 5 minutes prior to testing. The present study was designed to determine whether the CRF antagonist would also manifest a stress-protective effect when administered prior to application of the stressor.

\section{METHODS}

\section{Subjects}

Male, Wistar rats (Charles River) weighing 300 to $400 \mathrm{~g}$ were housed in groups of three in a colony room lighted from 0500 to 1700 hours with continuous access to rodent chow (Teklad) and water. Subjects were handled on arrival and acclimated to the animal quarters for one week prior to any experimental procedure.

\section{Surgery}

For the experiments measuring $\mathrm{ACTH}$ and corticosterone, fifty subjects were equipped with intravenous catheters suitable for blood sampling. Under halothane anesthesia ( $1 \%$ in oxygen), the left jugular vein was incised and a $3.5-\mathrm{cm}$ length of PE 10 tubing was inserted and secured with the tip in proximity to the heart. The enlarged (PE 50 tubing) output end of the catheter was closed with a removable occluder and passed out of an incision in back of the neck. Catheterized rats were single housed for a two-day post-surgical recovery period during which time catheters were flushed and filled with heparinized (1:5) physiological saline.

For experiments employing intracerebroventricular (ICV) injection, rats were surgically equipped with a single cannula aimed above the lateral ventricle. Anesthetized (Halothane, 1\% in oxygen) subjects were secured in a Kopf stereotaxic instrument where a 7-mm long, 23-gauge stainless steel guide cannula was lowered to within $1 \mathrm{~mm}$ of the ventricle and anchored to the skull with screws and dental cement. With the tooth bar $5.0 \mathrm{~mm}$ above interaural zero, implantation coordinates were $0.6 \mathrm{~mm}$ posterior to bregma, $3.2 \mathrm{~mm}$ below the skull surface at point of entry, and $\pm 2.0 \mathrm{~mm}$ lateral.

\section{ICV Injection Procedure}

After a 7-day post-surgical recovery period, cannula patency was confirmed by gravity flow through an 
8-mm, 30-gauge injector inserted through the guide to $1 \mathrm{~mm}$ beyond its tip. To perform an injection, $5 \mu \mathrm{l}$ of solution was infused by gravity over 30 seconds. The injector was left in place for 30 seconds to prevent backflow leakage, and the cannula was filled with a 7-mm stylet.

\section{Elevated Plus-Maze}

Subjects were placed facing toward an enclosed arm in the center of an Elevated Plus-Maze. This 5-minute test provided a computer automated measure of arm exploration (Heinrichs et al. 1992). Testing was conducted in a quiet, dedicated room that was dimmed to provide 22 to 350 lux of illumination on exposed arms of the maze and less than 1 lux within the enclosed arms. All experiments employed a between-subjects design in which separate groups of rats were tested on the plus-maze only once.

\section{Stressors}

Restrained subjects were confined individually for 60 minutes in hemi-cylindrical Plexiglas tubes $(8 \mathrm{~cm}$ diameter, $20 \mathrm{~cm}$ long). The swim stress procedure consisted of placing rats in a $45 \mathrm{~cm}$ tall, $30 \mathrm{~cm}$ wide cylindrical plastic container containing $30 \mathrm{~cm}$ of water maintained at 21 to $23^{\circ} \mathrm{C}$. After 2 minutes in the water, subjects were removed and briskly towel dried for 30 seconds. Social conflict stress began by placing a single, naive experimental rat in the cage $(44.5 \mathrm{~cm}$ wide $\times$ $66 \mathrm{~cm}$ deep $\times 38 \mathrm{~cm}$ high) of a resident male aggressor rat. The ensuing characteristic pattern of olfactory investigation and agonistic offensive and defensive behaviors was interrupted by the experimenters once a resident attack resulted in social defeat of the intruder rat. Social defeat was defined as the display of a submissive/supine posture after being attacked. Defeated intruders were then placed within a protective Plexiglas/wire mesh enclosure $(19 \mathrm{~cm}$ wide $\times 28 \mathrm{~cm}$ long $\times$ $17.5 \mathrm{~cm}$ high) and this enclosure was placed back inside the resident cage. This allowed the social conflict to resume and continue without physical contact or injury.

\section{Peptide/Drugs}

The $\alpha$-helical $\mathrm{CRF}_{9-41}$ was provided by Dr. Jean Rivier of the Salk Institute's Clayton Foundation Laboratories for Peptide Biology. The peptide was dissolved in distilled water adjusted to $\mathrm{pH}$ 6.7. Chlordiazepoxide (Sigma) was dissolved in $0.9 \%$ physiological saline. Alphaxalone, a gift from Glaxo Research Group UK, was suspended in saline mixed with 2 drops of Tween 80 .

\section{ACTH/Corticosterone Assay}

Blood was collected ( 0.3 to $0.5 \mathrm{ml}$ volume) in chilled tubes containing $2.5 \mu \mathrm{l}$ EDTA $(50 \mathrm{mg} / \mathrm{ml})$ and $2.5 \mu \mathrm{l}$ aprotinin $(125,000 \mathrm{KUI} / \mathrm{ml})$. Plasma ACTH (M.W. 4541.1) was determined using a two-site immunometric assay (Allegro HS ACTH, Nichols) with an intraassay variability of $3.2 \%$ and an inter-assay variability of $7.8 \%$. Plasma corticosterone (M.W. 346.5) was determined by radioimmunoassay (ICN Biochemicals) with intra- and inter-assay variability of less than $10 \%$. Endocrine samples were collected from 1000 to 1400 hours beginning 5 hours into the light phase of the circadian cycle.

\section{Procedure}

Plasma ACTH and corticosterone were assayed from blood samples drawn at four separate time points: basal ( 0 minutes), 1 hour after attachment of the catheter tether and placement in opaque cylinders $(15 \mathrm{~cm}$ in diameter, $40 \mathrm{~cm}$ high) situated in a quiet, dimly lit room and immediately prior to stressor exposure and 10, 20, and 60 minutes following initial exposure to the stressor. Stressor duration was 60 minutes for restraint, 2 minutes for swim, and 30 minutes for social conflict. Blood samples scheduled following the termination of swim and social stress were taken after replacement in the opaque cylinders. A control group for potential pituitary-adrenal activation produced by experimental procedures such as blood withdrawal and handling was briefly removed from and then replaced in the opaque cylinders. This procedure immediately followed the basal blood sample when experimental groups were handled and transported to separate rooms for stressor application.

For the experiments designed to examine behavioral reactivity to stress and administration of the CRF antagonist, 253 total subjects were used. For restraint stress, 66 subjects were first injected with $\alpha$-helical $\mathrm{CRF}_{9-41}(0,1,5$, or $25 \mu \mathrm{g} \mathrm{ICV})$ and then returned to the home cage (control group) or restrained (stress group) for 60 minutes prior to plus-maze testing. The behavioral effects of $\alpha$-helical CRF9-41 were examined concurrently in nonstressed control (Figure 3) and restraint stressed subjects (Figure 2) that shared a common vehicle-treated, nonstress control group. For swim stress, 42 subjects were first injected with $\alpha$-helical $\mathrm{CRF}_{9-41}(0,1,5$, or $25 \mu \mathrm{g} \mathrm{ICV})$ and then returned to the home cage (control group) for 8 minutes or replaced in the home cage and 5 minutes later exposed to swim stress (stress group) immediately prior to plus-maze testing. For social conflict, 50 subjects were first injected with $\alpha$-helical $\mathrm{CRF}_{9-41}(0,1,5$, or $25 \mu \mathrm{g} \mathrm{ICV})$ and returned to the home cage (control group) or exposed to social conflict (stress group) and tested on the plusmaze 30 minutes later. For the chlordiazepoxide experi- 
ment, 43 subjects were first injected with chlordiazepoxide ( 0 or $5 \mathrm{mg} / \mathrm{kg} \mathrm{IP}$ ) and then returned to the home cage (control group) or restrained (stress group) for 60 minutes prior to plus-maze testing. For the alphaxalone experiment, 50 subjects were first injected with alphaxalone $(0,4$, or $8 \mathrm{mg} / \mathrm{kg} \mathrm{IP})$ and then returned to the home cage (control group) or restrained (stress group) for 60 minutes prior to plus-maze testing.

\section{Statistical Analysis}

Percentage time on exposed arms relative to cumulative time on all four arms of the plus-maze was analyzed by two-way ANOVA with experimental treatment (control versus stress, dose of drug/peptide) and type of stressor (restraint, swim, social stressors) as between subject factors. Behavioral effects of restraint, swim, and social stressors and administration of chlordiazepoxide or alphaxalone were evaluated relative to separate, concurrent control groups for each of these five experimental treatments. Post hoc comparisons were performed using Newman-Keuls tests. Endocrine endpoints were analyzed by two-way ANOVA with between (type of stressor) and repeated (time point) subject factors, and individual means were compared using Dunnett's $t$-test.

\section{RESULTS}

As exhibited in Figure 1, there was a main effect of stress on ACTH release $[\mathrm{F}(3,46)=16.49, p<.001]$ with a significant increase in ACTH secretion over time $[\mathrm{F}(3,138)=89.52, p<.001]$ and a significant interaction of the two factors $[\mathrm{F}(9,138)=15.87, p<.001]$. Social, swim, and restraint stressors significantly elevated ACTH levels over time $[\mathrm{F}(3,138)=19.89, p<$ $.001 ; \mathrm{F}(3,138)=26.25, p<.001 ; \mathrm{F}(3,138)=69.75, p<$ $.001]$, whereas a handled control procedure did not $[F(3,138)<1, N S]$. In particular, both the restraint and swim stressors produced a larger elevation of plasma ACTH ten minutes following the initiation of stress than the social stressor $[t(46)=6.35, p<.01 ; t(46)=2.45$, $p<.05]$. Interestingly, the swim and restraint stress groups exhibited a significant decline in ACTH levels 20 and 60 minutes following the initiation of stress relative to the levels at 10 minutes $[\mathrm{F}(2,18)=30.6, p<.001$; $\mathrm{F}(2,26)=9.45, p<.001]$ whereas the social stress group did not $[F(2,45)=1.98$, NS $]$.

There was a main effect of stress on plasma corticosterone release [Figure 1; $\mathrm{F}(3,46)=33.47, p<.001$ ] with a significant increase in corticosterone over time $[\mathrm{F}(3,138)=97.77, p<.001]$ and a significant interaction of the two factors $[F(9,138)=13.66, p<.001]$. Social, swim, and restraint stressors each significantly elevated corticosterone levels over time $[\mathrm{F}(3,138)=24.57, p<$
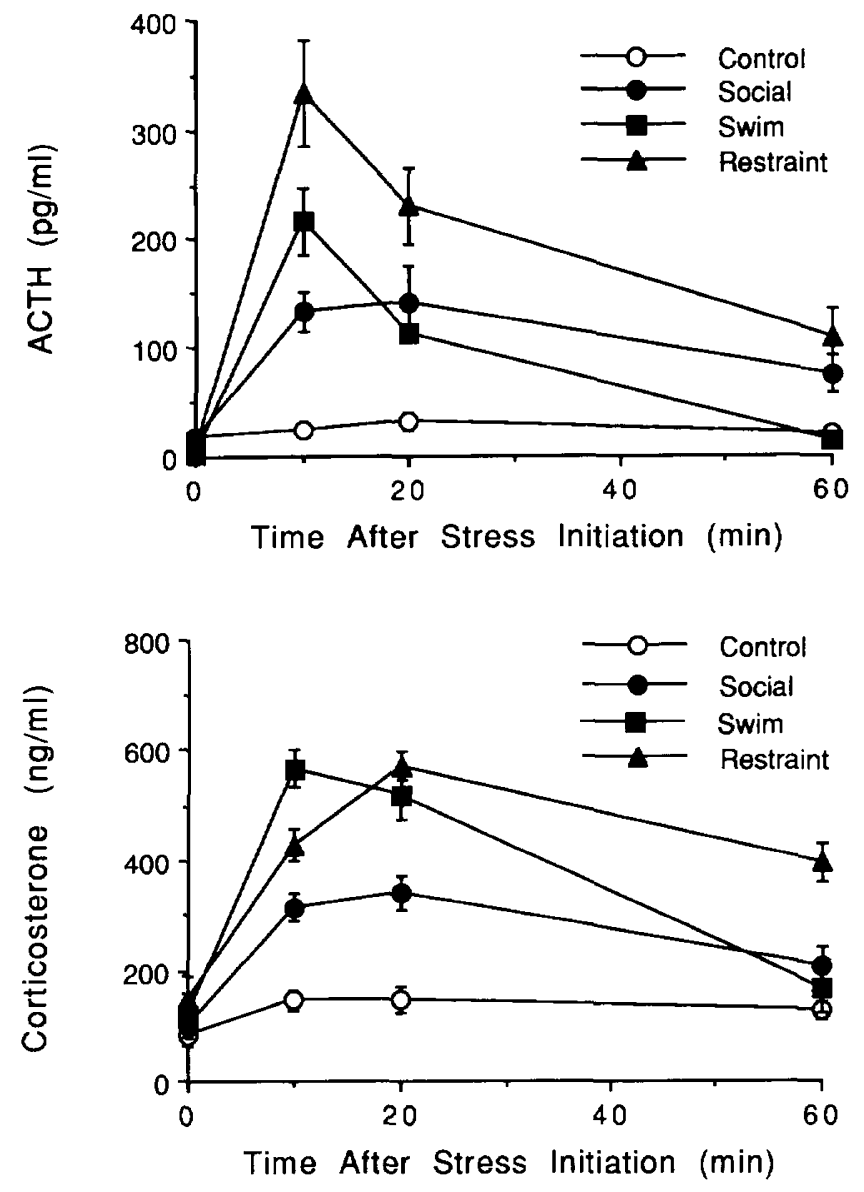

Figure 1. Mean ( \pm SEM) plasma levels of adrenocorticotropic hormone (ACTH, upper panel) or corticosterone (lower panel) sampled under basal conditions ( 0 minutes) or 10,20 , and 60 minutes following a control procedure $(n=18)$ or exposure to one of three different stressors: social $(n=16), \operatorname{swim}(n=$ $7)$, or restraint $(n=9)$.

$.001 ; \mathrm{F}(3,138)=48.65, p<.001 ; \mathrm{F}(3,138)=38.8, p<$ $.001]$, whereas a handled control procedure did not $[\mathrm{F}(3,138)=1.94$, NS $]$.

As exhibited in Figure 2, there was a main effect of experimental treatment $[\mathrm{F}(4,131)=4.28, p<.005]$ without an effect of the type of stressor employed $[\mathrm{F}(2,131)<1, \mathrm{NS}]$ or an interaction of the two factors $[F(8,131)<1, N S]$. The three stressors produced an overall significant reduction in the percentage of time spent on open arms of the plus-maze in vehicle-treated groups relative to respective nonstressed controls $(p<.05$, Newman-Keuls test). The 1 but not 5 or $25 \mu \mathrm{g}$ dose of $\alpha$-helical $\mathrm{CRF}_{9-41}$ reversed significantly the overall stress-induced reduction in percentage of time spent on open arms relative to stressed, vehicle treated-controls $(p<.05$, Newman-Keuls test). In contrast, $\alpha$-helical $\mathrm{CRF}_{9-41}$ administered in the absence of an experimental stressor (Figure 3) significantly decreased the per- 


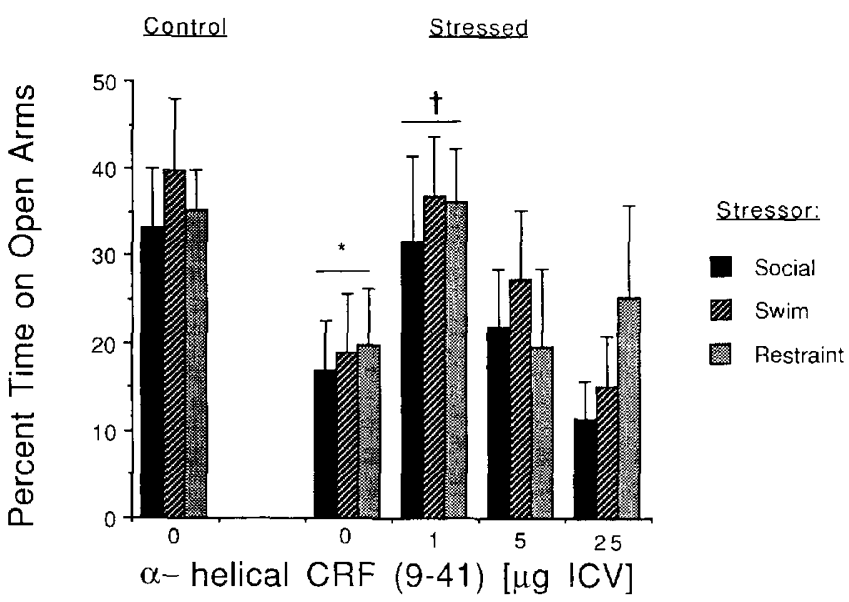

Figure 2. Mean ( \pm SEM) percent time spent on open arms of the elevated plus-maze in three separate experiments involving pre-stress administration of $\alpha$-helical CRF9-41: (1) 30 minutes after injection of the CRF antagonist in control $[0(n=$ 11) $\mu \mathrm{g}$ ICV] or social stress groups $[0(n=10), 1(n=10)$, $5(n=10)$, or $25(n=9) \mu \mathrm{g} \mathrm{ICV]}$; (2) 8 minutes after injection of the CRF antagonist in control $[0(n=10) \mu \mathrm{g}$ ICV] or swim stress groups $[0(n=9), 1(n=8), 5(n=8)$, or $25(n=7)$ $\mu \mathrm{g} \mathrm{ICV]}$; and (3) 60 minutes after injection of the CRF antagonist in control $[0(n=12) \mu \mathrm{g} I C V]$ or restrained groups $[0(n=15), 1(n=11), 5(n=6)$, or $25(n=6) \mu \mathrm{gICV}] .{ }^{*} p<$ .05 vs. vehicle-treated control groups; $+p<.05$ vs. vehicletreated, stressed groups.

centage of time spent on open arms $[\mathrm{F}(3,26)=4.88, p<$ .01].

As shown in Figure 4, restraint stress reduced the percentage of time spent on open arms of the plus-maze $[F(1,39)=4.30, p<.05]$, whereas chlordiazepoxide produced an overall increase in percentage time $[\mathrm{F}(1,39)=$ $10.71, p<.005]$ without an interaction of the two fac-

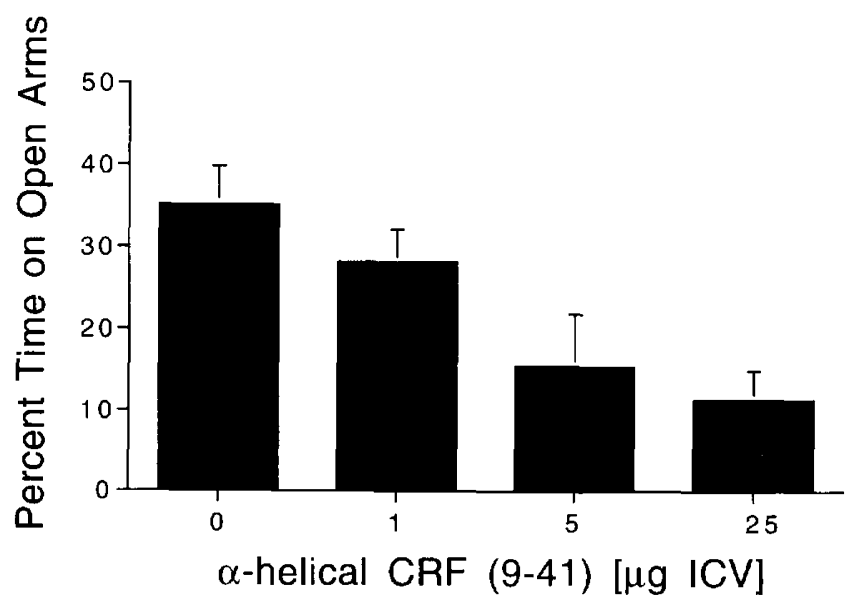

Figure 3. Mean $( \pm$ SEM) percent time spent on open arms of the elevated plus-maze 60 minutes after injection of $\alpha$-helical $\mathrm{CRF}_{9-41}$ in nonstressed controls $[0(n=12), 1(n=6), 5(n=$ $6)$, or $25(n=6) \mu \mathrm{g}$ ICV].
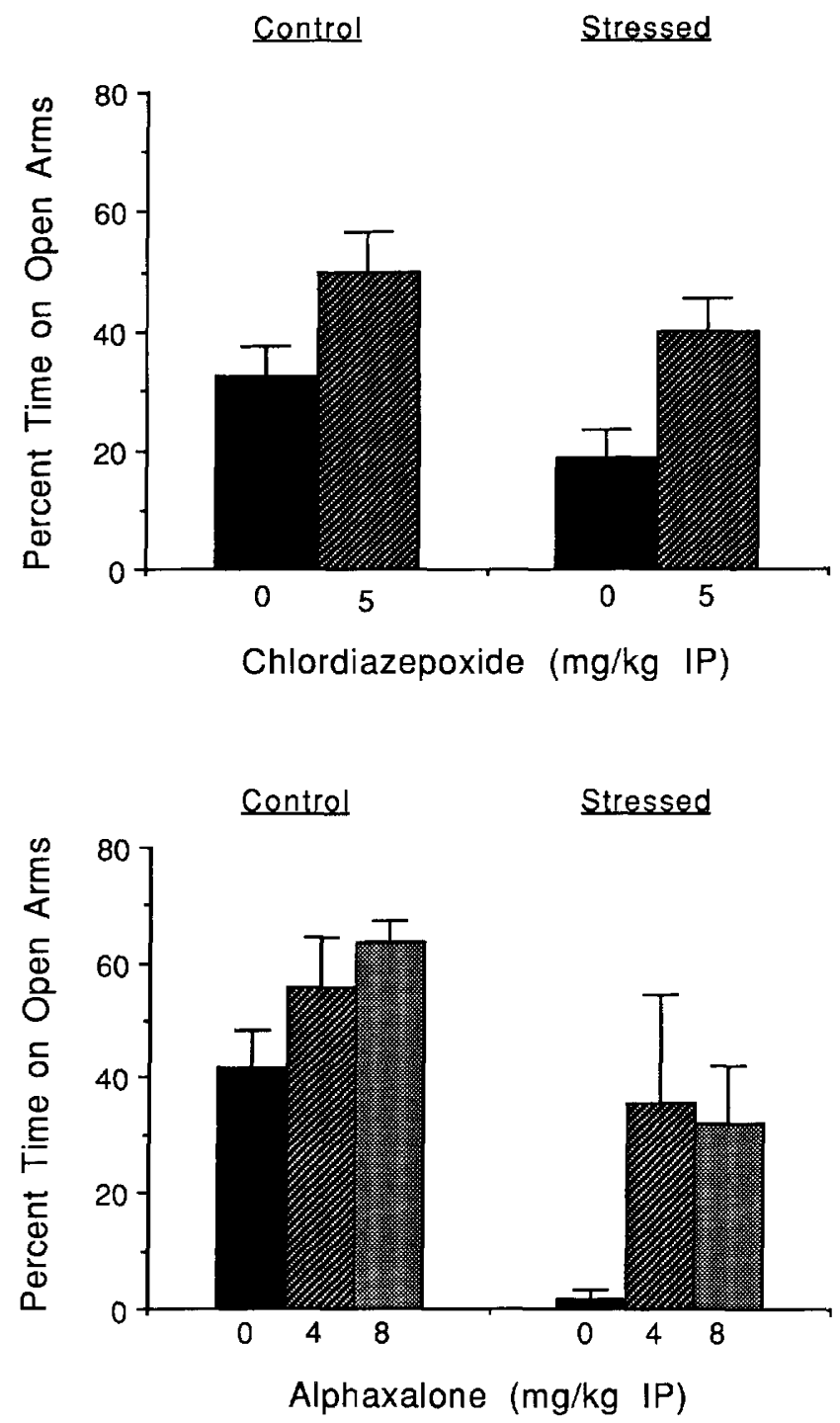

Figure 4. Mean ( \pm SEM) percent time spent on open arms of the elevated plus-maze 60 minutes after injection of either chlordiazepoxide (upper panel) in control $[0(n=8)$ or $5(n=$ $7) \mathrm{mg} / \mathrm{kg} \mathrm{IP}]$ or restrained groups [0 $(n=14)$ or $5(n=14)$ $\mathrm{mg} / \mathrm{kg} \mathrm{IP]}$ or administration of alphaxalone (lower panel) in control $[0(n=12), 4(n=4)$, or $8(n=8) \mathrm{mg} / \mathrm{kg} \mathrm{IP}]$ or restrained groups $90(n=5), 4(n=5)$, or $8(n=5) \mathrm{mg} / \mathrm{kg} \mathrm{IP]}$.

tors $[F(1,39)<1, N S]$. Restraint stress reduced the percentage of time spent on open arms of the plus-maze $[\mathrm{F}(1,44)=16.00, p<.001]$, whereas alphaxalone produced an overall increase in percentage time $[\mathrm{F}(2,44)=$ $4.72, p<.05$ ] without an interaction of the two factors $[\mathrm{F}(2,44)<1, \mathrm{NS}]$.

\section{DISCUSSION}

All three stressors employed in the present experiment induced the release of plasma ACTH, which serves as 
a humoral index of stressor intensity. Adrenocorticotropin release appears to be a constant feature of the response to most types of stressors (Gibbs 1984), and changes in pituitary-adrenal tone reflect the intensity of stimulation to which an organism is exposed (Hennessy and Levine 1978). Whereas restraint was found to be the most intense stressor in the present experiment, other comparative studies of stressor intensity suggest that a prone immobilization procedure (Pitman et al. 1988) and electric shock applied to the tail (Orr et al. 1990) are both more severe stressors than the present tube restraint procedure. These results and the present finding that plasma corticosterone levels that serve as an additional albeit more controversial index of stressor intensity (Keim and Sigg 1976; Natelson et al. 1981) revealed the same graded response to stress as ACTH values suggests that restraint, swim, and social stressors reflect different amounts of physiological stimulation in the rat.

A low $1 \mu \mathrm{g}$ dose of the CRF antagonist injected prior to stressor exposure attenuated the suppression in open arm exploration elicited on the plus-maze by restraint. Berridge and Dunn (1987) also demonstrated a reversal of the restraint stress-induced decrease in time spent in contact with novel stimuli in a multicompartment chamber using a $10 \mu \mathrm{g}$ dose of the CRF antagonist in mice. Interestingly, the data exhibited in Figure 3 and separate experiments in our laboratory indicate that the $1 \mu \mathrm{g}$ dose of $\alpha$-helical CRF - $_{-41}$ is without effect on the plus-maze in nonstressed controls, whereas higher 5 and $25 \mu \mathrm{g}$ doses of the CRF antagonist not only fail to produce an anti-stress action following restraint stress but produce a CRF-like partial agonist action in nonstressed controls (Baldwin et al. 1991; Heinrichs et al. 1992; Menzaghi et al. 1994). Moreover, the dual antistress and partial agonist actions of ICV-administered $\alpha$-helical CRF $9-41$ are also exerted following direct intracerebral administration (Heinrichs et al. 1992), are similar to the biphasic behavioral profile of CRF itself (Koob et al. 1993), and the partial agonist action is completely absent in a novel CRF antagonist (Menzaghi et al., 1994). Taken together, these results suggest that the behavioral action of the CRF antagonist is stressdependent at a $1 \mu \mathrm{g}$ dose which has no intrinsic action in nonstressed controls. This conclusion is consistent with previous results suggesting that there is no intrinsic effect of the CRF antagonist administered in effective anti-stress doses on performance in behavioral testing paradigms in the absence of a stressor such as novelty, electric shock, or drug withdrawal (Krahn et al. 1986; Shibasaki et al. 1988; Dunn and Berridge 1990; Baldwin et al. 1991).

A $1 \mu \mathrm{g} \mathrm{ICV}$ dose of the CRF antagonist also attenuated the anxiogenic-like behavioral response to a swim stressor. The same dose-dependent anti-stress action of the CRF antagonist was observed on the behavioral response to restraint. Although the 1,5 , and $25 \mu \mathrm{g} \mathrm{ICV}$ dose range of the CRF antagonist tested in the present experiments was adapted from effective anti-stress doses reported in the literature (see Dunn and Berridge 1990), doses lower than $1 \mu \mathrm{g}$ do not attenuate the suppression in exploration of the plus-maze produced by restraint (unpublished observations). Taken together, these results suggest that the CRF antagonist attenuated the suppression of exploration on the plus-maze when administered prior to initiation of restraint or swim stress and either 8 or 60 minutes prior to testing.

Pre-stress administration of the CRF antagonist in the present study reversed the anxiogenic-like behavioral effect of a social stressor using a lower dose $(1 \mu \mathrm{g})$ than that previously shown to effectively reverse social stress-induced suppression of exploratory behavior following post-stress administration of $\alpha$-helical $\mathrm{CRF}_{9-41}$ (25 $\mu \mathrm{g}$; Heinrichs et al. 1992). This dosedependent action of the CRF antagonist may reflect a change over time in the profile of behavioral and physiological responses to the social stressor. Resident exposure produces a less intense but more sustained rise in pituitary-adrenal activation than that induced by swim or restraint stressors, and ACTH/corticosterone levels remain significantly elevated in defeated animals for several hours following an aggressive encounter (Heinrichs et al., 1992; Merlo Pich et al. 1993). Maximal HPA activation occurs within 10 minutes of the initiation of restraint stress (Figure 1; De Souza and Van Loon 1985 ) but has a latency of 20 to 40 minutes following initiation of social conflict (Figure 1; Heinrichs et al. 1992; Merlo Pich et al. 1993). Because this physiological response to stress serves as a possible index of the rise and decay of the behavioral response to stress, one explanation for the increased potency of $\alpha$-helical $\mathrm{CRF}_{9-41}$ after pre-stress versus post-stress administration in the context of a social conflict stressor is that a larger dose of CRF antagonist is needed to alter the behavioral reactivity to stress as CRF system activation persists over the time since stress initiation. Moreover, as CRF antagonist administration was equally effective in attenuating the behavioral response to restraint, swim, and social stressors, one common denominator for the anxiogenic-like action of these diverse treatments may be the activation of endogenous brain CRF systems. This comprehensive anti-stress action of the CRF antagonist is consistent with Selye's original conception of stress as a nonspecific phenomenon (see Mason 1971). However, there exist several counterexamples to this axiom, such as the stressor specificity of the habituation to chronic stress (Kant et al. 1983).

Chlordiazepoxide reversed the effect of restraint and also elevated the open arm exploration of nonstressed controls, suggesting that the disinhibiting action of the dose of chlordiazepoxide tested in the present study on plus-maze performance is stress- 
independent. This nonspecific anxiolytic action in nonstressed controls probably reflects an effect on the response to novelty inherent in this particular behavioral paradigm. Because agonists of the benzodiazepine/GABA receptor complex attenuate anxiogenic-like behavioral effects of exogenous $\mathrm{CRF}$ administration and stress (Britton et al. 1985; Heinrichs et al. 1992), Britton et al. (1992) have hypothesized an interaction between benzodiazepine/GABA and CRF receptor systems. Although selective anti-stress effects of benzodiazepine treatment on plus-maze performance have been reported (Heinrichs et al. 1992), chlordiazepoxide and CRF antagonist likely modulate anxiogenic-like behavior via separate neuronal substrates because no antistress dose or any other dose of the CRF antagonist tested produced an anxiolytic effect in nonstressed controls.

Recently, the synthetic steroid anesthetic, alphaxalone, has been reported to increase open-arm exploration of the plus-maze (Britton et al. 1991) and to reverse the anxiogenic-like behavioral effect of a swim stressor and exogenous CRF administration on plusmaze performance and operant conflict behavior, respectively (Britton et al. 1992). Consistent with the stress-independent anxiolytic effect of chlordiazepoxide, alphaxalone pre-treatment completely reversed the anxiogenic-like behavioral effect of restraint stress and dose dependently disinhibited exploration of the plusmaze in nonstressed controls. This result provides a further contrast to the stress-dependent action of the CRF antagonist.

Although the stressors all produced an equivalent magnitude of suppression in exploration of the plusmaze, swim and restraint stressors possessed a greater capacity for stimulation of ACTH secretion than social defeat, suggesting that variations in stressor quality or severity differentially activate the hypothalamo-pituitary-adrenal axis. This dissociation of CRF-dependent behavioral and endocrine responses to stress supports previous work demonstrating a direct neurotropic role for endogenous CRF apart from the hypophysiotropic CRF system in regulating emotional behavior (Berridge and Dunn 1989; Heinrichs et al. 1992). Activation of extra-hypothalamic CRF may be more closely related to the particular type of response required in coping appropriately with a stressor than the type of stressor because stress-induced changes in appetitive and exploratory classes of behavior appear to be modulated by CRF (Dunn and Berridge 1990), whereas baseline operant conflict responding (Britton et al. 1986) and baseline acoustic startle reactivity (Swerdlow et al. 1989) appear not to be modulated by CRF. More specifically, centrally administered $\alpha$-helical $\mathrm{CRF}_{9-41}$ alters neither the rate of lever pressing in the punished component of the conflict paradigm when food reinforcement is paired with electric footshock nor the amplitude of the whole body flinch reflex in the startle paradigm produced by a loud, uncued tone. Hence, although both of these reports demonstrate the ability of $\alpha$-helical $\mathrm{CRF}_{9-41}$ to block the pro-conflict and startle-potentiating effects of CRF, there was no intrinsic effect of the $\mathrm{CRF}$ antagonist alone, suggesting again that endogenous CRF systems may not participate in mediating nonstressed baseline performance, performance that is disinhibited by benzodiazepines and other drugs acting on the GABA complex. Furthermore, since the stressors employed in the present study elicited a differential neuroendocrine response and manifested qualitatively distinct active versus passive coping strategies during stressor application, the present results support a generalized anti-stressor action of the CRF antagonist regardless of the type or intensity of response these stressors induce in other physiological systems.

\section{ACKNOWLEDGMENTS}

We thank Glaxo Research Group, UK, for the gift of alphaxalone and Dr. Jean Rivier for generously providing the $\alpha$-helical $\mathrm{CRF}_{9-41}$ This work was supported in part by grants NIDDK 26741 to G.F.K. and NIAAA $07456 / 06420$ to the Alcohol Research Center of The Scripps Research Institute. We thank Mr. Richard Schroeder for performing the ACTH and corticosterone assays. This is publication number $8233-\mathrm{NP}$ of The Scripps Research Institute.

\section{REFERENCES}

Baldwin HA, Rassnick S, Rivier J, Koob GF, Britton KT (1991): CRF antagonist reverses the "anxiogenic" response to ethanol withdrawal in the rat. Psychopharmacology 103:227-232

Berridge CW, Dunn, AJ (1987): A corticotropin-releasing factor antagonist reverses the stress-induced changes of exploratory behavior in mice. Horm Behav 21:393-401

Berridge CW, Dunn AJ, (1989): CRF and restraint-stress decrease exploratory behavior in hypophysectomized mice. Pharm Biochem Behav 34:517-519

Britton KT, Morgan J, Rivier J, Vale W, Koob G (1985): Chlordiazepoxide attenuates CRF-induced response suppression in the conflict test. Psychopharmacology 86:170-174

Britton KT, Lee G, Vale W, Rivier J, Koob GF (1986): Corticotropin releasing factor (CRF) receptor antagonist blocks activating and "anxiogenic" actions of CRF in the rat. Brain Res 369:303-306

Britton KT, Page M, Baldwin H, Koob GF (1991): Anxiolytic activity of steroid anesthetic alphaxalone. J Pharm Exp Ther 258:124-129

Britton KT, McLeod S, Koob GF, Hauger R (1992): Pregnane steroid alphaxalone attenuates anxiogenic effects of corticotropin releasing factor and stress. Pharm Biochem Behav 41:399-403

De Souza EB, Van Loon GR (1985): Differential plasma, 
$\beta$-endorphin, $\beta$-lipotropin, and adrenocorticotropin responses to stress in rats. Endocrinology 116:1577-1586

Dunn AJ, Berridge CW (1990): Physiological and behavioral responses to corticotropin-releasing factor administration: Is CRF a mediator of anxiety or stress responses? Brain Res Rev 15:71-100

Farabollini F, Albonetti ME, Aloisi AM, Facchinetti F, Grasso G, Loki L, Lupo C, Muscettola M (1993): Immune and neuroendocrine response to restraint in male and female rats. Psychoneuroendocrinology 18:175-182

Gibbs DM (1984): Dissociation of oxytocin, vasopressin and corticotropin secretion during different types of stress. Life Sci 35:487-491

Heinrichs SC, Merlo Pich E, Miczek KA, Britton KT, Koob GF (1992): Corticotropin-releasing factor antagonist reduces emotionality in socially defeated rats via direct neurotropic action. Brain Res 581:190-197

Hennessy MB, Levine S (1978): Sensitive pituitary-adrenal responsiveness to varying intensities of psychological stimulation. Physiol Behav 21:295-297

Kant GF, Bunnell BN, Mougey EH, Pennington LL, Meyerhoff JL (1983): Effects of repeated stress on pituitary cyclic AMP, and plasma prolactin, corticosterone and growth hormone in male rats. Pharm Biochem Behav 18:967-971

Keim KL, Sigg EB (1976): Physiological and biochemical concomitants of restraint stress in rats. Pharm Biochem Behav 4:289-297

Koob GF, Heinrichs SC, Merlo Pich E, Menzaghi F, Baldwin H, Miczek K, Britton KT (1993): The role of corticotropin-releasing factor in behavioral responses to stress. In Corticotropin-Releasing Factor, Ciba Foundation Symposium 172, Wiley, pp. 277-289

Krahn DD, Gosnell BA, Grace M, Levine AS (1986): CRF antagonist partially reverses CRF- and stress-induced effects on feeding. Brain Res Bull 17:285-289

Mason JW (1971): A re-evaluation of the concept of "nonspecificity" in stress theory. J Psychiatr Res 8:323-333
Menzaghi F, Howard RL, Heinrichs SC, Vale W, Rivier J, Koob GF (1994): Characterization of a novel and potent corticotropin-releasing factor antagonist in rats. J Pharm Exp Ther 269:564-572

Merlo Pich E, Heinrichs SC, Rivier C, Miczek K, Fisher DA, Koob GF (1993): Blockade of pituitary-adrenal axis activation induced by peripheral immunoneutralization of corticotropin-releasing factor does not affect the behavioral response to social defeat stress in rats, Neuropsychopharmacology 18:495-507

Natelson BH, Tapp WN, Adamus JE, Mittler JC, Levin BE (1981): Humoral indices of stress in rats. Physiol Behav 26:1049-1054

Natelson BH, Ottenweller JE, Cook JA, Pitman D, McCarty R, Tapp WM (1988): Effect of stressor intensity on habituation of the adrenocortical stress response. Physiol Behav 43:41-46

Orr TE, Meyerhoff JL, Mougey EH, Bunnell BM (1990): Hyperresponsiveness of the rat neuroendocrine system due to repeated exposure to stress. Psychoneuroendocrinol 15:317-328

Pitman DL, Ottenweller JE, Natelson BH (1988): Plasma corticosterone levels during repeated presentation of two intensities of restraint stress: Chronic stress and habituation. Physiol Behav 43:47-55

Rivier J, Rivier C, Vale W (1984): Synthetic competitive antagonists of corticotropin-releasing factor: Effect on ACTH secretion in the rat. Science 224:889-891

Shibasaki T, Yamauchi N, Kato Y, Masuda A, Imaki T, Hotta M, Demura H, Oono H, Ling N, Shizume K (1988): Involvement of corticotropin-releasing factor in restraint stress-induced anorexia and reversion of the anorexia by somatostatin in the rat. Life Sci 43:1103-1110

Swerdlow NR, Britton KT, Koob GF (1989): Potentiation of acoustic startle by corticotropin-releasing factor (CRF) and by fear are both reversed by $\alpha$-helical CRF (9-41). Neuropsychopharmacology 2:285-292 